\title{
An Empirical Study on the Intentional Behaviors of Healthcare Consumers in a Telehealthcare System in Taiwan
}

By Wei-Min Huang

National Chung Cheng University

Abstract- Due to an aging population and the impact of chronic disease, health insurance costs in Taiwan have increased year by year. In order to allow people access to great medical care from home or within their community, the Taiwanese government has promoted a number of telehealthcare policies. Most related research emphasizes the technology involved in such policies, but this study considers instead the combination of a technology acceptance model, a health belief model, and measures of trust within the community to probe the Taiwanese telehealthcare system.

This study was developed to examine factors that affect the usage, attitudes, and intentions of healthcare consumers within a telehealthcare system. 284 responses were collected via an online survey and analyzed using SPSS 23 and smart PLS2.0.

The results showed that perceived ease of use and usefulness were affected by social trust, perceived usefulness was affected by perceived ease of use, users' attitudes were affected by perceived ease of use and perceived usefulness, and user intention was affected by perceived usefulness, perceived seriousness, perceived benefits, and cues to action.

Keywords: telehealthcare, technology acceptance model, health belief model.

GJHSS-G Classification: FOR Code: 139999

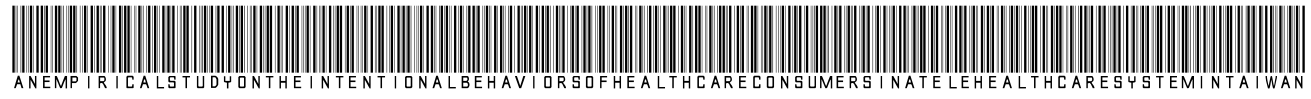

Strictly as per the compliance and regulations of:

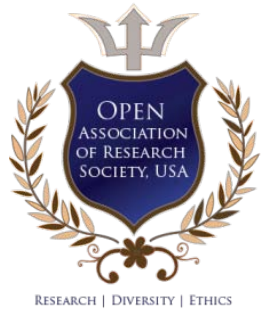

(c) 2021. Wei-Min Huang. This research/review article is distributed under the terms of the Attribution-NonCommercialNoDerivatives 4.0 International (CC BY-NC-ND 4.0). You must give appropriate credit to authors and reference this article if parts of the article are reproduced in any manner. Applicable licensing terms are at https://creativecommons.org/licenses/by-nc$\mathrm{nd} / 4.0 \%$ 


\title{
An Empirical Study on the Intentional Behaviors of Healthcare Consumers in a Telehealthcare System in Taiwan
}

\author{
Wei-Min Huang
}

Abstract Due to an aging population and the impact of chronic disease, health insurance costs in Taiwan have increased year by year. In order to allow people access to great medical care from home or within their community, the Taiwanese government has promoted a number of telehealthcare policies. Most related research emphasizes the technology involved in such policies, but this study considers instead the combination of a technology acceptance model, a health belief model, and measures of trust within the community to probe the Taiwanese telehealthcare system.

This study was developed to examine factors that affect the usage, attitudes, and intentions of healthcare consumers within a telehealthcare system. 284 responses were collected via an online survey and analyzed using SPSS 23 and smart PLS2.0.

The results showed that perceived ease of use and usefulness were affected by social trust, perceived usefulness was affected by perceived ease of use, users' attitudes were affected by perceived ease of use and perceived usefulness, and user intention was affected by perceived usefulness, perceived seriousness, perceived benefits, and cues to action. Keywords: telehealthcare, technology acceptance model, health belief model.

\section{InTRODUCTION}

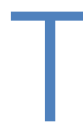
o address healthcare needs of an aging population with a low birth rate and the impacts of chronic disease, the Taiwanese government has been working to improve its existing healthcare environment within the scope of its national budget. Maintaining the existing quality of care while upgrading to a more cost-effective model is important to society. According to the World Health Organization (WHO), a country in which those 65 years old or older comprise at least $7 \%$ of the total population can be called aging. Taiwan's Elders' Welfare Law also expressly states that only those over the age of 65 may be called elderly.

According to statistics from the Interior Ministry of Social Affairs, at the end of September 1993 Taiwan's elderly population over 65 years was about 148.5 million people, accounting for 7.09 percent of the population and surpassing the aging society index set by WHO the based on population structure, average life expectancy, and other factors. With the advancement of healthcare

Author: Graduate Institute of Healthcare Information Management, College of Management, National Chung Cheng University, Taiwan.

e-mail: weimin950@gmail.com information technology and popularization of national quality of life improvement initiatives, telehealth is urgently needed to face current concerns that the elderly and chronically ill population will continue to increase.

At the end of 2020, Taiwan's elderly population comprised $15.5 \%$ of the total population, and current trends estimate in 20 years the proportion of elderly people in Taiwan will have doubled. It's therefore critical that the Taiwanese government promotes long-distance healthcare solutions so that elderly or chronically ill patients can get good medical care at home or in their community.

In recent years, the top ten causes of death, including from acute illness and chronic disease, have seen a significant increase especially in the number of deaths due to cardiovascular illness, cerebrovascular illness, and diabetes. As such, the ratio of healthcare medical expenses spent on these patients has also increased. According to Curtin and Lubkin (1995), a chronic disease "is a symptom of some uncertain time internal disease caused by the disease and can only be part of a long-term recovery."

The National Health Insurance (NHI) in Taiwan was established in 1995 and has since led to an insurance rate of more than $99 \%$. Regardless of age, citizens are provided universal care. However, because of the impact of chronic disease and aging, Taiwan's average per capita national health expenditures have increased year by year, with NHI's financial pressure growing.

In Taiwan, hypertension is an important public health problem with regard to the associated risk of stroke and cardiovascular events. However, the results of a population-based high blood pressure (BP) prevalence survey in Taiwan revealed that $68 \%$ of Taiwanese with hypertension were aware of their disease, but only $22.9 \%$ had good BP control. Telehealth is the use of technology to allow communication between patients and care providers, while patients remain outside the clinical environment, such as in their home (Ju, Chen \& Hsu, 2019).

In recent years, global healthcare industry patterns have changed the way healthcare services are delivered. From the traditional hospital bedside service, we've now turned to address the lives of patients discharged from the hospital, and at-home care 
services have shifted the main focus of attention from acute care to a prevention-based health perspective.

Information and communications technology allow for the broad application of health, medical, and care-related services and are important aspect of strategies to address healthcare needs moving forward. In line with industry trends in global health technology and services, government policy is promoting telehealthcare (THC), information and communications technology, and the use of electronic medical equipment to allow people to receive healthcare and preventive health services within their community or home.

\section{il. Literature Review}

\section{a) Telehealthcare}

Telemedicine or telehealthcare uses electronic communication and information technology to provide medical care when patients and caregivers cannot be simultaneously at one location. In addition to its use in care, the scope of application may also include health promotion, disease and accident prevention, reeducation of personnel, patient and family health education, counseling, management, and administrative business. The US Department of Health and Human Services (DHHS), notes that personal and at-home healthcare services are a part of comprehensive healthcare that aims to enhance, maintain, and restore health, or otherwise minimize the effects of disability and disease.

\section{i. Telemedicine's definition}

Telemedicine is defined as "by electronic communications technology, the exchange of medical information from one place to another to transport and to improve the health of patients by American Telemedicine Association (ATA, 2011). Chau and $\mathrm{Hu}$ (2002) consider telemedicine as the use of information, communication, biomedical technology, and geographical separation between the groups in order to support, promote, or improve healthcare services, events or cooperation through the electronic transmission of information and expertise. Distant nursing care and care service areas located in the telehealth community or at-home care are all considered telehealth home care (THC) (Burtt, 1997).

\section{b) Evolution of Telemedicine}

In the early 1900s Willem Einthoven invented a method of telehealth that involved broadcasting graphics files. Beginning in 1910 at New York Presbyterian Hospital, the method was widely used for the transmission of ECGs. After World War II, urban hospitals began using telehealth for diagnostics. In 1960, as computers and telematic technology matured, telemedicine services began to not only break down geographic barriers, but also improve healthcare delivery models. In 1959, the United States began using
TV image communication facilities for medicine. In the same year, the first famous telemedicine program started at the University of Nebraska by a clinician using two-way action tests and other information with neurological medical students across campus. With the establishment of a telemedicine link with Norfolk State Hospital in 1964, speech therapy, neurological examination, psychiatric diagnosis difficult cases, case notes, case studies and educational training led to a foreign telemedicine evolution. In addition to reducing the cost of upgrading technology, telemedicine in the late 1980s began to accelerate development. Telemedicine programs can now be divided into clinically relevant and non-clinically relevant categories. A review of foreign experience in the implementation of telemedicine and related documents show that modern telemedicine faces many difficulties and challenges, including whether telehealth technology can sufficiently meet patient needs, resistance of medical staff, patient resistance, medical regulatory issues, and the protection of patient data and payment methods, among others (Kovner \& Hardy, 1996; Kuo \& Delvecchio, 2001).

Several studies have demonstrated that individuals with dementia and their caregivers find technology based monitoring (Farina et al., 2019; Kikhia et al., 2018) and care management (Dang et al., 2018; Gately et al., 2020) acceptable. Furthermore, several studies have found that these interventions are feasible and can aid in providing patient-centered care that results in improved quality of life (QoL) and reduced caregiver burden (Holthe et al., 2018).

In order to understand the effectiveness of the government in the promotion of long-distance healthcare services, this study investigates levels of user demand, acceptance within scientific and technological theory, the effect of a telehealthcare system users on the system's acceptance, and expectations for the government to develop long-distance in the future. Ultimately, the aim of this study is to inform the development of healthcare policies to develop a better telehealthcare system in Taiwan.

Davis (1989) adapted the Theory of Reasoned Action (TRA) as the basis for the development of the Technology Acceptance Model (TAM) in which subjective perception of the usefulness (Usefulness) and usability (Ease of Use) are independent variables to investigate user attitudes and faith in science and technology using the relationship between intention and actual use.

\section{c) Theory of Reasoned Action}

Fishbein and Aizen (1975) proposed the TRA theoretical framework grounded in the psychology, prediction, and interpretation of actual human behavior. The theory attributes much of human behavior to acts of faith - when faith changes, behavior changes. Development of this theory in 1980 defined "attitude", 
"behavioral intentions", and "behavior" as the three facets of the "subjective norms" used to construct a complete theory chart that "behavioral intentions "I will be" attitude "and" subjective norms "impact and indirect impact on the actual" behavior "(Ajzen \& Fishbein, 1980). Figure 1 illustrates the TRA theoretical framework.

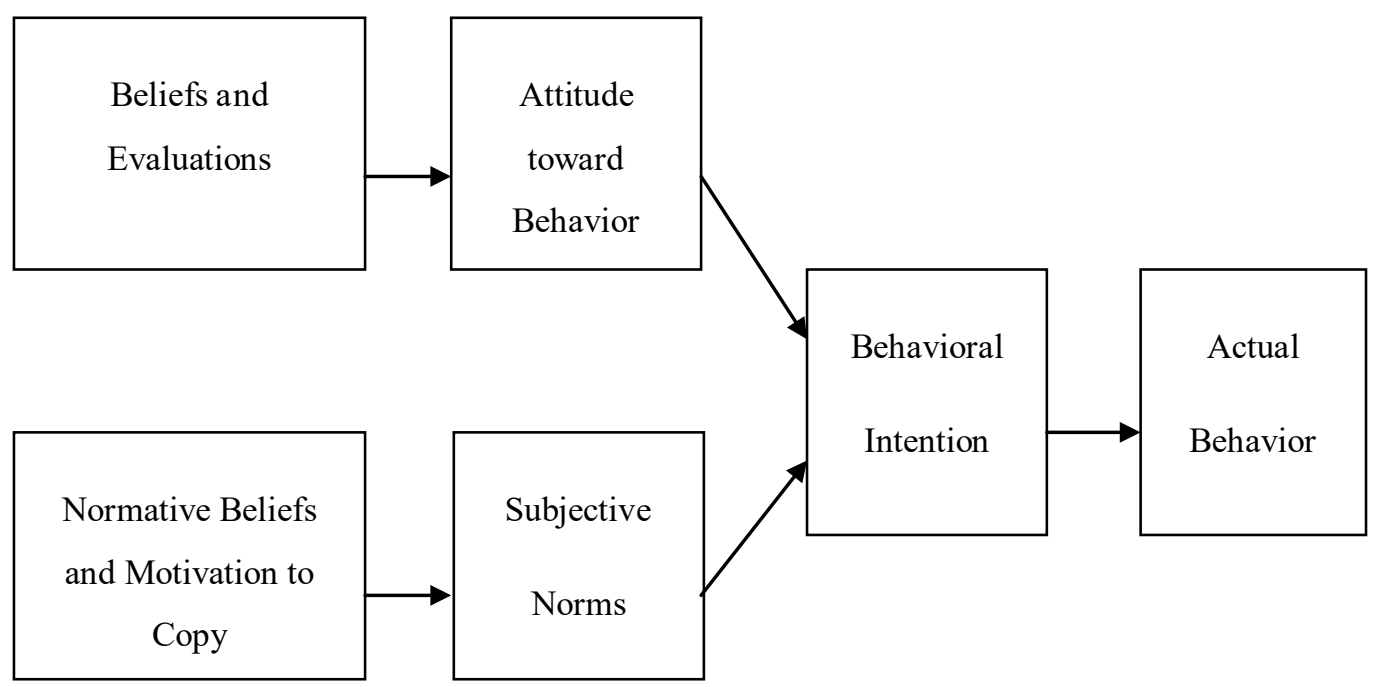

Source: Fishbein and Aizen (1975). Belief, Attitude, Intention and Behavior: An Introduction to Theory and Research. Reading, MA: Addison-Wesley.

\section{Figure 1: Theory of Reasoned Action}

\section{d) Technology Acceptance Model}

Davis (1989) contributed to the theory of reasoned action (TRA) with expected theoretical models, self-efficacy theory, and a Technology Acceptance Model (TAM). He believes TAM's "behavioral intentions" is a determining factor affecting the use of information technology, adding that behavioral intentions are directly affected by "perceived usefulness" and "behavior and attitude". In addition, "behavioral intention" and "subjective norms" are not included in the TAM because Davis considers subjective norms and subjective perception of external social pressure to give itself, and thus produce individual behavior, but because people's subjective perceptions often change along with information systems in an organized environment, users may be reluctant but will inevitably comply with directive executives and experts.

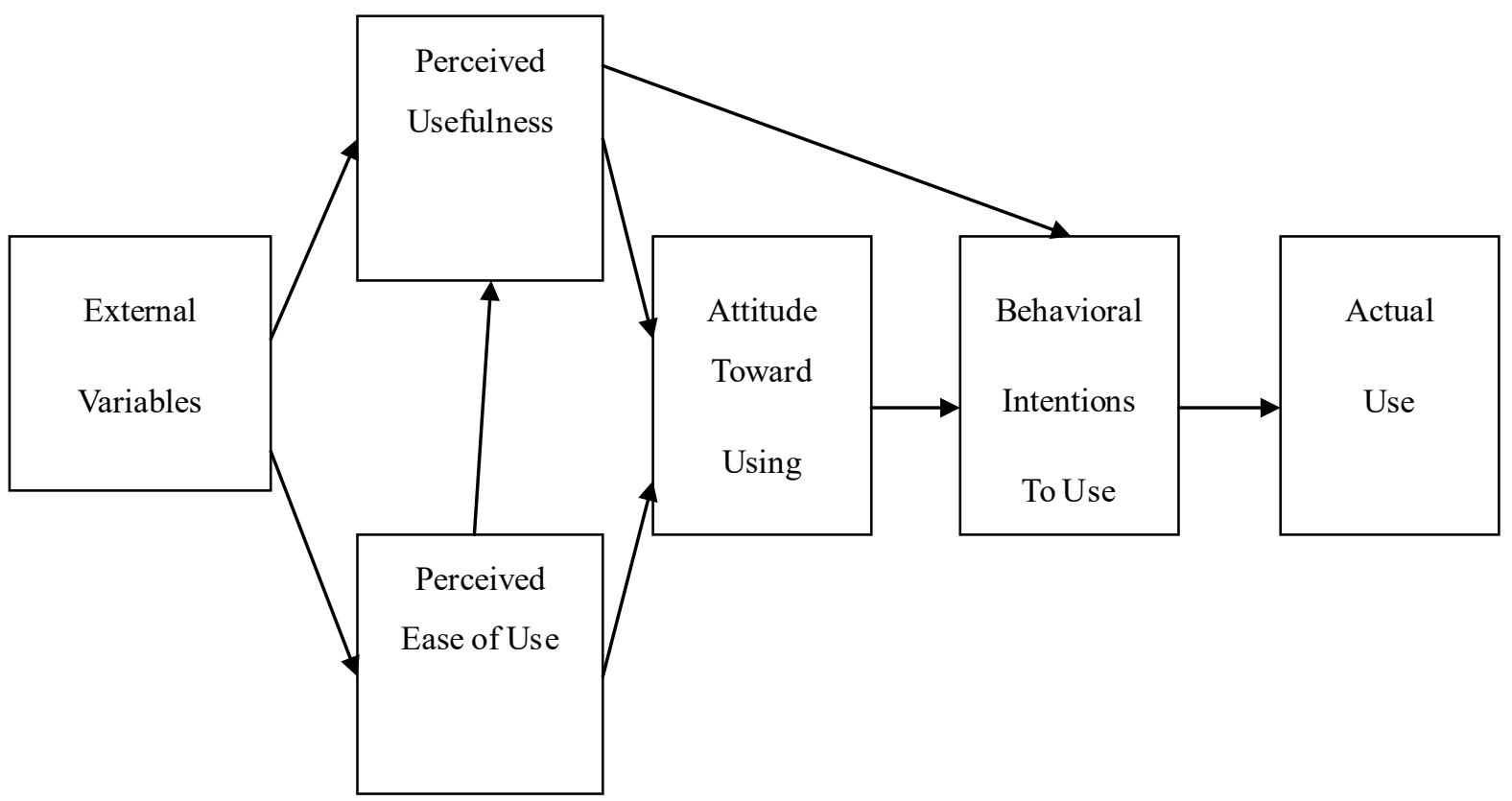

Source: Davis (1989). Perceived Usefulness, Perceived Ease of Use, and User Acceptance of Information Technology. MIS Quarterly, 13(3), 319-340.

Figure 2: Technology Acceptance Model 
Davis, Bagozzi, and Warshaw (1989) applied TRA and TAM of 107 corporate MBA (Master of Business Administration, MBA) in an empirical study on the relationship between users and the intended use of information systems. The results are as follows: (a) behavioral intentions can effectively predict the actual behavior of a computer user; (b) perceived usefulness is the main determinant of behavioral intention; (c) cognitive behavioral intentions for ease of use is second only to the cognitive effects of usefulness, which means cognitive behavior associated with the system's ease of use is lower than its perceived usefulness. Studies have shown the explanatory power of TAM to be better than TRA. In addition, TRA predicts "intent to use" at the social and psychological levels, but with respect to the use of information technology TAM has more appropriate explanatory power.

After many academic studies, current applications of the Technology Acceptance Model have been extended to the medical and healthcare industry (Chau \& Hu, 2002; Pai \& Huang, 2010; Kowitlawakul, 2011), e-government websites (Teo, Srivastava, \& Jiang, 2008), online banking (Bhattacherjee, 2001; Yousafzai, Foxall, Pallister, \& John, 2010), and electronic and mobile commerce. Legris and Collerette (2003) summarized past research on TAM the model explains only about $40 \%$ of information systems. TAM alone does not clearly explain how information systems are integrated into the course of human and social change, important variables and facets of innovation adoption. Such factors must be considered in order to further increase the explanatory power of TAM.

e) The Health Belief Model Theory

The Health Belief Model (HBM) was developed in the early 1950's by Hochbaum, Kegeles, Leventhal, Rosenstock and other social psychologists, as an application of concepts from Lewin's Field Theory to interpret theoretical models of preventive health behaviors. Lewin's Field Theory states that everyone is present in a field as a negative value composed of two living spaces, plus or minus the value in this field, with health as a positive value and I'll be negative in value. When a person feels an impending sickness (conscious and unconscious suffering of varying severity), he or she may consider taking action in order to avoid illness brought about by the negative threats. Health Belief Model Theory is based on the Theory of Expected Value (Value Expectancy Theory) as the basis for motivation (motivation) and cognition (perception) to predict and explain health-related behaviors, namely when an individual wants to avoid illness or wants to become healthy, and the use of special health actions to prevent or ameliorate expected diseases (Rosenstock et al, 1988). The Health Belief Model was originally intended to explain why the average person will accept preventive care and screening activities, but because of its wide applicability it was proposed to explain the health behavior of people overall and is often used in research on disease behavior, doctor-patient relationships, and health education.

The Health Belief Model has been extended from its original focus on preventive health behavior to personal daily health behaviors. The Social Cognitive Theory (SCT) proposed by Bandura includes the selfefficacy concept of identity (self-efficacy) as a factor of long-term change. Only when one has confidence will it be possible to enact change, with the degree of confidence measured in terms of self-efficacy. Rosenstock, Strecher and Becker (1988) suggest that self-efficacy be added to the Health Belief Model such that the self-efficacy that individuals have for their ability to perform an act of faith can model the likelihood of the individual to take action (Janz, Champion, \& Strecher, 2002).

\section{f) Trust Theory}

The ability of telehealth home healthcare services to gain user trust with respect to the security of user data, the maintenance of user privacy, sustainability of the service, and so on, is bound to affect the adoption of the telehealthcare system and its use. Therefore, this study includes facets of trust to explore whether the user trust affect the impact of behavioral intentions on health systems.

\section{g) Trust of the Doctor-Patient Relationship}

With increased medical knowledge among the general public, the relationship between patient care and medical attention is also increasingly relevant to the development of the doctor-patient relationship. Trust is an important factor, as a trust relationship between the patient and medical staff may reduce patient anxiety (Thorne \& Robinson, 1988). In telehealthcare, the patient and medical staff conduct the majority of healthcare behaviors through information technology and network communications. Therefore, in a new doctor-patient relationship, the patient's trust in telehealthcare workers is also very important.

Mohseni and Lindstrom's (2007) medical research on social and institutional trust shows that patients do not need to have any medical expertise at the scope of the clinical or technical level. Social trust is said to be increased by actions such as listening, respect, care, and assistance in managing the disease. Su, Tsai, and Hsu's (2013) work studied the institution of trust and social trust as endogenous variables outside the Technology Acceptance Model. Their results show trust as an important facet of intent. However, within the scope of this study, only a single set of medical institutions, and therefore patients, are considered to investigate the mechanism of trust and social trust among community and home-based healthcare systems and telehealth users. 


\section{Research Methodology}

\section{a) Research Framework}

This empirical study on users of the current telehealthcare system in Taiwan uses a structured internet-based questionnaire survey. The questionnaire was developed and translated based on the literature with a five-point Likert (Likert) scale with five options for each question, namely "strongly disagree", "disagree", "ordinary", "agree", and "strongly agree", to accurately reflect the feelings of the respondents.

This study was aimed to explore the factors affecting the behavioral intentions of people in a telehealthcare system. The architecture of the study is based mainly on Davis's (1989) model of technology acceptance and Wixom and Todd's (2005) claim that technology receiving mode extends three major development on the basis of the model. The exogenous variables of "institutional trust" and "social trust" in the Health Belief Model are included in this study. Variables include the "conscious suffering sex", "conscious threatening", "conscious action of interest", "conscious action disorder", and "action cues" as endogenous variables, in addition to "perceived usefulness", "perceived ease of use", and "attitude". The following is the operational definitions of the independent variables used in this study.

Table 1: Operational Definitions

\begin{tabular}{|c|c|c|}
\hline Variable & Operational Definition & Reference \\
\hline Institutional Trust & Telehealthcare system users trust in healthcare providers & $\begin{array}{l}\text { Mohseni and } \\
\text { Lindsorm (2007) }\end{array}$ \\
\hline Social Trust & Telehealthcare system users trust in the social environment & $\begin{array}{l}\text { Mohseni and } \\
\text { Lindsorm (2007) }\end{array}$ \\
\hline $\begin{array}{l}\text { Perceived Ease of } \\
\text { Use }\end{array}$ & $\begin{array}{l}\text { Telehealthcare system users believe that the system is easy to } \\
\text { use }\end{array}$ & Davis (1989) \\
\hline $\begin{array}{l}\text { Perceived } \\
\text { Usefulness }\end{array}$ & $\begin{array}{l}\text { Telehealthcare system users think that the degree of use of the } \\
\text { system can improve the effectiveness of care. }\end{array}$ & Davis (1989) \\
\hline Attitude & $\begin{array}{l}\text { Telehealthcare system users have positive or negative feelings } \\
\text { towards the system }\end{array}$ & $\begin{array}{l}\text { Fishbein and Ajzen } \\
\text { (1975) }\end{array}$ \\
\hline $\begin{array}{l}\text { Perceived } \\
\text { Susceptibility }\end{array}$ & $\begin{array}{l}\text { Telehealthcare system so that users get other diseases self- } \\
\text { awareness." }\end{array}$ & $\begin{array}{l}\text { Rosenstock(1994) } \\
\text { and Janz et al. } \\
(2002)\end{array}$ \\
\hline Perceived Severity & $\begin{array}{l}\text { Telehealthcare system users for the seriousness of the health of } \\
\text { self-awareness. }\end{array}$ & $\begin{array}{l}\text { Rosenstock(1994) } \\
\text { and Janz et al. } \\
(2002)\end{array}$ \\
\hline Perceived Benefits & $\begin{array}{l}\text { Telehealthcare system users believe the system may reduce the } \\
\text { impact of the possible occurrence of the disease }\end{array}$ & $\begin{array}{l}\text { Rosenstock(1994) } \\
\text { and Janz et al. } \\
(2002)\end{array}$ \\
\hline Perceived Barriers & $\begin{array}{l}\text { Telehealthcare system users believe the system increases costs } \\
\text { in terms of mental or spiritual awareness. }\end{array}$ & $\begin{array}{l}\text { Rosenstock(1994) } \\
\text { and Janz et al. } \\
(2002)\end{array}$ \\
\hline Cues to Action & Telehealthcare system users' change in health behaviors & $\begin{array}{l}\text { Rosenstock(1994) } \\
\text { and Janz et al. } \\
\text { (2002) }\end{array}$ \\
\hline
\end{tabular}

\section{b) Hypotheses}

i. Trust

When a person is at risk, trust creates positive thoughts and feelings of reliability (Boon \& Homelmes, 1985). Dirks (1999) states that trust is an expectation or belief that another person or institution has good will and is reliable. Mohseni and Lindsorm's (2007) study on the doctor-patient relationship in terms of trust and confidence in institutions of social trust, i.e., institutional trust, shows that patients do not need to have any medical expertise at the clinical or technical level. Social trust refers to trust someone else encourages in patients via listening, respect, care, and assistance in managing the disease. Su, Tsai and Hsu's (2013) study indicates that trust is an important facet in behavioral intentions in the use of telehealthcare. Therefore, the following fourpoint hypothesis is proposed:

H1: Telehealthcare system users' institutional trust has a positive effect on perceived ease of use.

H2: Telehealthcare system users' institutional trust has a positive impact on perceived usefulness.

H3: Telehealthcare system users' social trust has a positive effect on perceived ease of use.

H4: Telehealthcare system users' social trust has a positive effect on perceived usefulness.

\section{ii. Perceived usefulness and perceived ease of use}

The results of Davis (1993), Igbaria et al. (1997), and Sørebø and Eikebrokk (2008) indicate that perceived ease of use will positively affect perceived 
usefulness. This means that when telehealth users do not need to spend a lot of time to learn how to operate a telehealthcare service system, they will feel that this system is useful and can help them effectively improve their own health status. This study is based on the following hypotheses:

H5: For telehealth users, perceived ease of use has a positive effect on perceived usefulness.

Davis (1993), Mathieson, Peaccock and Chin (2001), and Vijayasarathy (2004) all found that when information technology can effectively improve work efficiency and does not take much effort to learn, users will have more positive feelings towards the technology. For the healthcare system to effectively improve personal health and reduce pain, users should not have to spend too much effort learning it. This leads to the following hypotheses:

H6: Telehealth users' perceived usefulness has a positive impact on their attitude and behavior.

H7: Telehealth users' perceived ease of use of the healthcare system has a positive impact on their attitude and behavior.

Davis (1993), Igbaria et al. (1997), and Mathieson et al. (2001) found that if users believe a system can effectively improve their performance they will have higher behavioral intentions. Therefore, if people believe that a telehealthcare service system can improve their health, there will be a high willingness to use the telehealthcare service system. This study therefore proposes the following hypothesis:

H8: Telehealth users' perceived usefulness of the telehealthcare service system has a positive effect on behavioral intentions.

\section{iii. Behavior and Attitude}

Ajzen's (1985) study found that the higher an individual's positive attitude, the higher their desire to take action. Davis et al. (1989), Legris et al. (2003), Vijayasarathy (2004) and Chakraborty, and Hu and Chi (2008) all found that when an individual has a positive attitude towards the use of new technology, behavioral intentions with respect to the system will be higher. Therefore, if telehealth user attitudes are positive they will have a higher willingness to use the system. Based on this, this study proposes the following hypothesis:

H9: Telehealthcare users' attitude and behavior has a positive impact on their intention of use of a longdistance healthcare service system.

\section{iv. Perceived Susceptibility and Perceived Severity}

When a person feels sick (conscious and unconscious suffering of severity), they will consider taking action in order to avoid futher illness brought about by the negative threats, for example by consciously adopting healthy sexual behavior. A positive effect is possible when individuals are already aware that they have a disease and may engage in healthy behaviors to prevent its getting worse (Fung, 1998; Friedman et al, 1998). When patients feel there are possible health threats, this may affect their use of a telehealthcare system when seeking health-related assistance. Therefore, according to this view, the present study proposes the following hypothesis:

H10: Telehealth users' conscious suffering will positively affect their behavioral intentions in their use of a telehealthcare system.

Becker (1974) and Anderson (1968) consider personal perceptions of one's own health status as an important factor affecting health behavior. When one encounters what they believe to be potential risk factors, one will tend to engage in health checks. So, regardless of the severity of the disease, patients are affected by their subjective perceptions. This study therefore proposes the following hypothesis:

H11: Telehealth users' conscious seriousness of the care system users positively affect their behavioral intentions and use of the telehealthcare system.

\section{v. Perceived Benefits and Perceived Barriers}

Bandura et al. (1997a) proposed that when any act of self is seen as beneficial, one will try to engage in this behavior. This belief may be affected by norms and pressure on individuals, and different social groups may act differently. In the health belief model, the stronger the conscious action of interest, the easier it is to perform some action. So the benefits of a telehealthcare system should be presented people to use, for example: deterioration of the disease, mitigation symptoms, increased quality of life. This study proposes the following hypothesi:

H12: Conscious interest action in a telehealthcare system will positively affect behavioral intentions and use of the system.

Rosenstock (1966) claims that hindering health behaviors and the cost it takes to produce a desired effect will reduce personal health-seeking behavior change intentions. So, when promoting a telehealthcare service, there may be to make use of this system to produce spending behavior, and thus reduce their willingness to use this system of. In the health belief model, the stronger barriers are to conscious action, the more impossible it is to take action. Therefore, this study presents the following hypothesis:

H13: The conscious mobility impairments of a telehealthcare system will negatively affect the behvioral intentions and use of the system.

\section{vi. Cues to Action}

Rosenstock (1966) pointed out that if no relevant health information is disseminated, action cues may trigger one of the key factors in health behavior. The action trail is divided into internal and external cues; internal refers to personal effects, such as physical discomfort and symptoms, and external refers to social 
factors, including physician recommendations, relatives' encouragement, or media education. Falomir (1999) also pointed out that social impact can help change health behavior. Therefore, this study presents the following hypothesis:

H14: Users' action cues have a positive impact on the behavioral intentions and use of a telehealthcare system.

\section{c) Research Design}

The purpose of the present study is to investigate the factors affecting the use of a telehealthcare system. This study focuses on at-home and community-based long-distance healthcare system users. A questionnaire was distributed among the online community using relevant social networks.

\section{Data Analysis and Results}

The study was designed according to methods to use the healthcare system through the Telehealth user for the study, because the home or communitybased healthcare system is difficult for the user Telehealth unified Surveying, therefore payment on the Internet questionnaire, in order to ensure that users actually used Telehealthcare system, the Internet questionnaire of this study is limited to a specific Telehealthcare community discussion. Questionnaire in the beginning of 2020 administrated questionnaire, after four months of surveyperiod 296 questionnaires were invalid questionnaires and the remaining 284 valid questionnaires. Data analysis and processing is conducted using SPSS 23.0 statistical analysis and SmartPLS 2.0 software for statistical analysis of the questionnaire.

\section{a) Structural analysis of samples}

The study questionnaire was a structured questionnaire and the basic information of respondents to those who are nominal scale of measurement types, the research carried out using SPSS 23.0 descriptive statistics and results of basic data analysis are described below.

\section{b) Demographic information of Telehealthcare system} users

According to statistical analysis of sample data research, a total of four people were aged 20 years old or younger, accounting for $1.4 \%$ of all samples; a total of 76 were $21-40$ years old, accounting for $26.8 \%$ of the total sample; a total of 160 people were aged 41-64 years, representing $56.3 \%$ of all samples; a total of 44 people were over the age of 65 , accounting for $15.5 \%$ of the total sample. The majority respondents were 41-64 years old. A total of 165 respondents were men, accounting for $58.1 \%$ of all samples, and a total of 119 were women, accounting for 41.9 per cent of the total sample. The majority of respondents were therefore male. As for education, education following a total of 46 countries, accounting for $16.2 \%$ of all samples; a total of 110 respondents completed up to senior high school, accounting for $38.7 \%$ of all samples; a total of 45 respondents had a college education, accounting for $15.8 \%$ of all samples; higher levels of education were attained by more than a total of six people, accounting for $2.1 \%$ of all samples. The majority of respondents to the questionnaire were therefore educated up to high school vocational education.

A total of 59 respondents reported an occupation in the healthcare system, accounting for $20.8 \%$ of the total sample. 12.0 percent, or 34 of the total sample, work in the the information technology industry. There are a total of 32 service sector employees accounting for $11.3 \%$ of all samples, and a total of 30 free industry accounting for $10.6 \%$ of all samples. Manufacturing and students of all 29 people accounted $10.2 \%$ of the total sample, housewives were 24 people, $8.5 \%$ of the total sample. Those in the financial sector accounted for $8.1 \%$ or 23 people of all samples, and a total of six military and government officials accounted for $2.1 \%$ of all samples. The majority of respondents to this survey were employed in healthcare. Telehealth user experience with the system ranged from 1-2-years total, 69 respondents accounting for $24.3 \%$ of the total sample, followed by less than 58 months accounting for $20.4 \%$ of the total sample. 49 respondents had more than two years' experience, accounting for $17.3 \%$ of the total sample, and a total of 58 people, accounting for $16.2 \%$ of the total sample, reported 1-3 months' experience. Experience of 4-6 months was reported by a total of 35 people accounting for $12.3 \%$ of the total sample. $6-1$ years a total of 27 people representing $9.5 \%$ of the total sample. Respondents used long-distance healthcare system for a maximum of 1-2 years. Reported frequency of use of a telehealthcare system include occasional (once a week) for a total of 139 respondents, $48.9 \%$ of all samples, followed by regular (1 2-3 times a week) use reported by a total of 74 respondents, $26.1 \%$ of all samples, and infrequently (once a month) use reported by a total of 36 people accounting for $12.7 \%$ of all samples. A total of 35 people use telehealthcare every day, $12.3 \%$ of the total sample. Most respondents indicated their frequency of use of a telehealthcare system as occasional (once a week).

\section{c) Reliability and Validity}

Reliability refers to the measure of credibility of questionnaire item, mainly in Cronbach's alpha values to measure the results of the questionnaire in terms of paragraph consistency or stability. Reliability analysis is mainly judged by compliance and standard error of measurement size. If items were asked two or more times the same measurement, the result of its higher degree of similarity is measured again, representing a higher reliability. Therefore, an $\alpha$ of 0.7 represents 
measurement results with high reliability. If $\alpha$ is between 0.7 to 0.35 , said CITIC degree. $\alpha$ less than 0.35 represents a lower reliability; such results should be rejected as less relevant (Champney, 1995).

In this study, Cronbach's alpha values for each variable are between 0.70 to 0.87 , indicating that each has high reliability, and the whole questionnaire's Cronbach's Alpha coefficient is 0.820 . Overall, there is a high reliability and high consistency and stability of this questionnaire, as seen in Table 2 below.

Table 2: Reliability Analysis

\begin{tabular}{|c|c|c|}
\hline Variable & Cronbach's Alpha & Cronbach's Alpha \\
\hline Institutional Trust & 0.747 & \\
\hline Social Trust & 0.719 & \\
\hline Perceived Ease of Use & 0.744 & \\
\hline Perceived Usefulness & 0.740 & \multirow{3}{*}{0.820} \\
\hline Attitude & 0.790 & \\
\hline Perceived Susceptibility & 0.708 & \\
\hline Perceived Severity & 0.737 & \\
\hline Perceived Benefits & 0.743 & \\
\hline Perceived Barriers & 0.866 & \\
\hline Cues to Action & 0.827 & \\
\hline Behavior Intention & 0.724 & \\
\hline
\end{tabular}

\section{d) Validity Analysis}

i. Content Validity

This refers to the measurement of content relevance. After the draft is completed, through the guidance of academic experts, medical practitioners and other medical fields have a considerable degree of understanding of experts to examine the question in the questionnaire items, the questionnaire will be amended semantic confusion and discomfort of the Department to ensure that the questionnaire Identify and improve content validity.

\section{ii. Construct Validity}

This refers to the measurement of reasoning abilities or abstract or traits and can be divided into convergent validity and discriminant validity.

\section{iii. Convergent Validity}

Measured via factor loadings (Factor Loading) and the average variance extracted amount (Average
Variance Extracted, AVE) with a threshold value of 0.5 to test and ensure trustworthiness. Factor loadings are usually factors (Factor Analysis) Analysis (Kaiser, 1974).

Prior to factor analysis, one must first coduct a KMO (Kasier-Meyer-Olkin sampling quantity relevance number) and Bartlett spherical test. If the $\mathrm{KMO}$ value is less than 0.5 , indicating that two variables cannot be used to explain other variables, they should not factor into analysis; on the contrary, larger $\mathrm{KMO}$ are more suitable for applications and factor analysis (Kaiser, 1974). The KMO value is 0.785 in this study. The results of this study indicate scale projects of common factors, suitable for factor analysis, and a spherical test shows a chi-square value of 3715.809 , up significantly, referring to the correlation matrix between parent groups with a common factor presence and representation suitable for factor analysis. This is shown in Table 3.

Table 3: KMO and Bartlett Test

\begin{tabular}{|c|c|c|}
\hline \multicolumn{2}{|c|}{ Kaiser-Meyer-Olkin } & .785 \\
\hline \multirow{3}{*}{ Bartlett } & chi square distribution & 3715.809 \\
\cline { 2 - 3 } & $\mathrm{df}$ & 406 \\
\cline { 2 - 3 } & significant & .000 \\
\hline
\end{tabular}

The factor analysis of this study uses principal component analysis (Principal Component Analysis) and the factors taken at right angles to the shaft axis method (Orthogonal Rotaion) for maximum number (Varimax) variation data analysis. In addition, Hair et al. (2006) pointed out that if the sample size is between 150 200, factor loadings (Factor Loading) need to be fully accepted in more than 0.45 , but in general, one may begin with 0.5 as the standard value analysis. The sample size of this study is 284 . As seen inTable 4-11, the results show the factor loadings are in compliance with standards.

In addition, use of a composite reliability (CR) confirmatory factor in the average variance extracted (AVE) was conducted for validity testing. This is a combination of reliability if the composite reliability value potential variables are greater than 0.6. The average variance extracted is generally 0.5 as a standard. If it is 
greater than 0.5, this item asked to correctly measure the extent of a potential error is a measure variables and will be greater than that caused by mutation. This represents convergent validity (Fornell \& Larcker, 1981).

The results are shown in Table 4 . In a combination of reliability measures, each dimension is greater than 0.6, indicating that each variable measures latent variables with internal consistency and good reliability. The AVE value in part found in 11 configurations surface in 10 standard. The average variance extracted obstacle facets conscious action alone is less than 0.5. According to Fornell and Larcker (1981), when the AVE value is less than 0.5, if the combination is higher than the letter of the facets 0.6 or more, and still has a convergent validity. Therefore, all factors in this study show good convergent validity.

Table 4: AVE and Composite Reliability

\begin{tabular}{|c|c|c|c|c|}
\hline Variable & Terms & AVE & Composite Reliability & Factor Loading \\
\hline \multirow[t]{3}{*}{ Institutional Trust } & IT1 & \multirow[t]{3}{*}{0.5645} & \multirow[t]{3}{*}{0.7723} & 0.8225 \\
\hline & IT2 & & & 0.9530 \\
\hline & IT3 & & & 0.7530 \\
\hline \multirow{3}{*}{ Social Trust } & ST1 & \multirow[t]{3}{*}{0.6353} & \multirow{3}{*}{0.8381} & 0.8935 \\
\hline & ST2 & & & 0.7042 \\
\hline & ST2 & & & 0.7821 \\
\hline \multirow[t]{3}{*}{ Perceived Ease of Use } & PEU1 & \multirow[t]{3}{*}{0.6638} & \multirow[t]{3}{*}{0.8552} & 0.8646 \\
\hline & PEU2 & & & 0.8181 \\
\hline & PUE3 & & & 0.7581 \\
\hline \multirow[t]{3}{*}{ Perceived Usefulness } & PU1 & \multirow[t]{3}{*}{0.6665} & \multirow[t]{3}{*}{0.8557} & 0.9071 \\
\hline & PU2 & & & 0.8270 \\
\hline & PU3 & & & 0.7019 \\
\hline \multirow[t]{3}{*}{ Attitude } & ATT1 & \multirow{3}{*}{0.7129} & \multirow[t]{3}{*}{0.8806} & 0.9171 \\
\hline & ATT2 & & & 0.8818 \\
\hline & ATT3 & & & 0.7213 \\
\hline \multirow[t]{3}{*}{ Perceived Susceptibility } & PSU1 & \multirow[t]{3}{*}{0.6311} & \multirow[t]{3}{*}{0.8355} & 0.8067 \\
\hline & PSU2 & & & 0.6826 \\
\hline & PSU3 & & & 0.8812 \\
\hline \multirow[t]{3}{*}{ Perceived Severity } & PSE1 & \multirow[t]{3}{*}{0.6601} & \multirow[t]{3}{*}{0.8531} & 0.8326 \\
\hline & PSE2 & & & 0.8533 \\
\hline & PSE3 & & & 0.7476 \\
\hline \multirow[t]{3}{*}{ Perceived Benefits } & PBE1 & \multirow[t]{3}{*}{0.5502} & \multirow[t]{3}{*}{0.7726} & 0.6193 \\
\hline & PBE2 & & & 0.9946 \\
\hline & PBE3 & & & 0.5272 \\
\hline \multirow{3}{*}{$\begin{array}{c}\text { Perceived } \\
\text { Barriers }\end{array}$} & PBA1 & \multirow[t]{3}{*}{0.4220} & \multirow[t]{3}{*}{0.6469} & 0.5955 \\
\hline & PBA2 & & & 0.5520 \\
\hline & PBA3 & & & 0.9349 \\
\hline \multirow[t]{3}{*}{ Cues to Action } & CTA1 & \multirow[t]{3}{*}{0.7345} & \multirow[t]{3}{*}{0.8920} & 0.7933 \\
\hline & CTA2 & & & 0.8301 \\
\hline & CTA3 & & & 0.9408 \\
\hline Behavior Intention & INT1 & 0.6247 & 0.8316 & 0.6852 \\
\hline & INT2 & & & 0.7846 \\
\hline & INT3 & & & 0.8881 \\
\hline
\end{tabular}

iv. Discriminant Validity (Discriminant Validity)

Discriminant validity and convergent validity are opposite to one another.

Discriminant validity is used to test the degree of correlation between variables and different factors with respect to the average variance extracted (AVE) amount of each factor of the square root of the correlation matrix. If the value is greater than the other factors of the correlation coefficient, it indicates that the factor is unlike other variables (Chin \& Newsted, 1999).
The results are shown in Table 5. The data shows facets of variable of this study are related to other facets of variable differ from each other. 
Table 5: The Square Root of the Correlation Matrix

\begin{tabular}{|c|c|c|c|c|c|c|c|c|c|c|c|}
\hline & IT & ST & PEU & PU & ATT & PSU & PSE & PBE & PBA & CTA & INT \\
\hline IT & 0.7513 & & & & & & & & & & \\
\hline ST & 0.0081 & 0.7970 & & & & & & & & & \\
\hline PEU & 0.0871 & 0.2834 & 0.8147 & & & & & & & & \\
\hline PU & 0.0927 & 0.2924 & 0.4924 & 0.8163 & & & & & & & \\
\hline ATT & 0.0993 & 0.2440 & 0.6991 & 0.4474 & 0.8443 & & & & & & \\
\hline PSU & 0.0721 & 0.2488 & 0.6533 & 0.3675 & 0.4906 & 0.7944 & & & & & \\
\hline PSE & 0.0917 & 0.2739 & 0.7641 & 0.5707 & 0.5930 & 0.5674 & 0.8124 & & & & \\
\hline PBE & 0.0731 & 0.0420 & 0.2188 & 0.0220 & 0.1923 & 0.1180 & 0.1294 & 0.7417 & & & \\
\hline PBA & 0.0237 & 0.0429 & 0.0362 & 0.0193 & 0.0054 & 0.0202 & 0.0292 & 0.0369 & 0.6496 & & \\
\hline CTA & 0.0043 & 0.1128 & 0.0232 & 0.0246 & 0.0345 & 0.0292 & 0.0397 & 0.0372 & 0.0320 & 0.8570 & \\
\hline INT & 0.0588 & 0.0500 & 0.0793 & 0.0854 & 0.1432 & 0.0787 & 0.0975 & 0.1163 & 0.1784 & 0.2204 & 0.7903 \\
\hline
\end{tabular}

\section{v. Structural Equation Modeling Analysis}

According to data analysis in SmartPLS 2.0, a structural model test estimated and predicted the path coefficients. A path coefficient test uses the software's pre-test method SmartPLS BootStrap. Predictive power of the model is estimated using $R^{2}$. The correlation analysis results are shown below.

\section{vi. Path Coefficient Test}

After the path analysis coefficient is tested using BootStrap, the number of samples within the sample is repeated 200 times to calculate the path coefficient $(\beta)$ and $t$ value. The path coefficient can show the strength and direction of the relationship between the study variables. A positive coefficient indicates positive correlation. Otherwise there is an inverse correlation. The results from the study show that in the path between the two significant relationship between the two facets of the relationship are all positive relationship. In addition, the $t$ value can be found through a statistical $p$-value conversion in order to determine whether the hypotheses of this study are significant. However, usually a $t$ value $p$ value is the normal correlation. If the sample size is greater than $120, \mathrm{t}$ distribution will be close to a normal distribution. In general, close to the norm or an insignificant $t$ value uses the following judgment criteria: $\mathrm{t}>1.645^{*}, \mathrm{t}>1.96^{* *}, \mathrm{t}>2.58^{* \star *}$, $t>3.29 * * \star *$.

The results are shown in Table 6. Perceived ease of use and perceived usefulness are not significant, and consciously suffering of conscious action is not an obstacle to significant behavioral intentions. The rest show a significant relationship.

Table 6: Path Analysis

\begin{tabular}{|c|c|c|c|}
\hline Relationship & $(\boldsymbol{\beta})$ & t-value & p-value \\
\hline $\begin{array}{l}\text { Institutions trust } \rightarrow \\
\text { Perceived ease of use }\end{array}$ & 0.030 & 0.504 & $p>0.1$ \\
\hline $\begin{array}{l}\text { Institutions trust } \rightarrow \\
\text { Perceived usefulness }\end{array}$ & 0.038 & 0.636 & $p>0.1$ \\
\hline $\begin{array}{l}\text { Social trust } \rightarrow \\
\text { Perceived ease of use }\end{array}$ & 0.265 & 6.606 & $\mathrm{p}<0.001^{\star \star \star \star}$ \\
\hline $\begin{array}{l}\text { Social trust } \rightarrow \\
\text { Perceived usefulness }\end{array}$ & 0.269 & 4.700 & $\mathrm{p}<0.001^{\star \star \star \star}$ \\
\hline $\begin{array}{l}\text { Perceived ease of use } \rightarrow \\
\text { Perceived usefulness }\end{array}$ & 0.473 & 9.016 & $\mathrm{p}<0.001^{* * * *}$ \\
\hline $\begin{array}{l}\text { Perceived usefulness } \rightarrow \\
\text { Attitude }\end{array}$ & 0.433 & 8.056 & $\mathrm{p}<0.001^{\star \star \star \star}$ \\
\hline $\begin{array}{l}\text { Perceived ease of use } \rightarrow \\
\text { Attitude }\end{array}$ & 0.681 & 15.635 & $\mathrm{p}<0.001^{\star \star \star \star}$ \\
\hline $\begin{array}{l}\text { Perceived usefulness } \rightarrow \\
\text { Behavior Intention }\end{array}$ & 0.645 & 1.6731 & $\mathrm{p}<0.1^{*}$ \\
\hline Attitude $\rightarrow$ Behavior Intention & 0.510 & 2.679 & $\mathrm{p}<0.01^{\star \star \star}$ \\
\hline $\begin{array}{l}\text { Susceptibility Perceived } \rightarrow \\
\text { Behavior Intention }\end{array}$ & 0.072 & 1.209 & $p>0.1$ \\
\hline $\begin{array}{l}\text { Perceived Severity } \rightarrow \\
\text { Behavior Intention }\end{array}$ & 0.295 & 2.657 & $\mathrm{p}<0.01^{* \star *}$ \\
\hline $\begin{array}{l}\text { Perceived Benefits } \rightarrow \\
\text { Behavior Intention }\end{array}$ & 0.202 & 2.185 & $p<0.05^{\star *}$ \\
\hline $\begin{array}{l}\text { Perceived Barriers } \rightarrow \\
\text { Behavior Intention }\end{array}$ & 0.036 & 0.598 & $p>0.1$ \\
\hline $\begin{array}{l}\text { Cues to Action } \rightarrow \\
\text { Behavior Intention }\end{array}$ & 0.131 & 2.219 & $p<0.05^{\star \star}$ \\
\hline
\end{tabular}

$t>1.645^{*}, t>1.96^{* *}, t>2.58^{* * *}, t>3.29^{* * * *}$

$p<0.1^{*}, p<0.05^{* *}, p<0.01 * * *, p<0.001^{* * * *}$ 
vii. Predictive Power of the Model Estimation

The predictive power of the model is estimated using SmartPLS 2.0 Algorithm method of analysis, but only to test the prediction degree PLS whole pattern of permeability coefficient $R^{2}$, which unlike the SEM can be adapted to understand the extent of the cut through the entire pattern detection. The $R^{2}$ value refers to the exogenous variables and can explain the endogenous variable percentage of variance, representing the predictive power of the model. The standard value is between 0 and 1 . Higher values indicate a better model. The $R^{2}$ values of this study are greater than 0.5 , indicating that this model has good explanatory power. $R^{2}$ values for perceived ease of use, perceived usefulness, behavior and attitude, and behavioral intention, respectively, are 57\%,55\%, 64\%, 59\% as shown in Table 7.

Table 7: Explanatory Ability

\begin{tabular}{|c|c|}
\hline Contruct & $\mathrm{R}^{2}$ \\
\hline Perceived ease of use & 0.572313 \\
\hline Perceived usefulness & 0.546341 \\
\hline Attitude & 0.635278 \\
\hline Behaveior Intention & 0.594426 \\
\hline
\end{tabular}

The results of path analysis for the overall study architecture are shown in Figure 3. The dashed line

represents an insignificant $p$-value. The solid line represents a significant $p$-value.

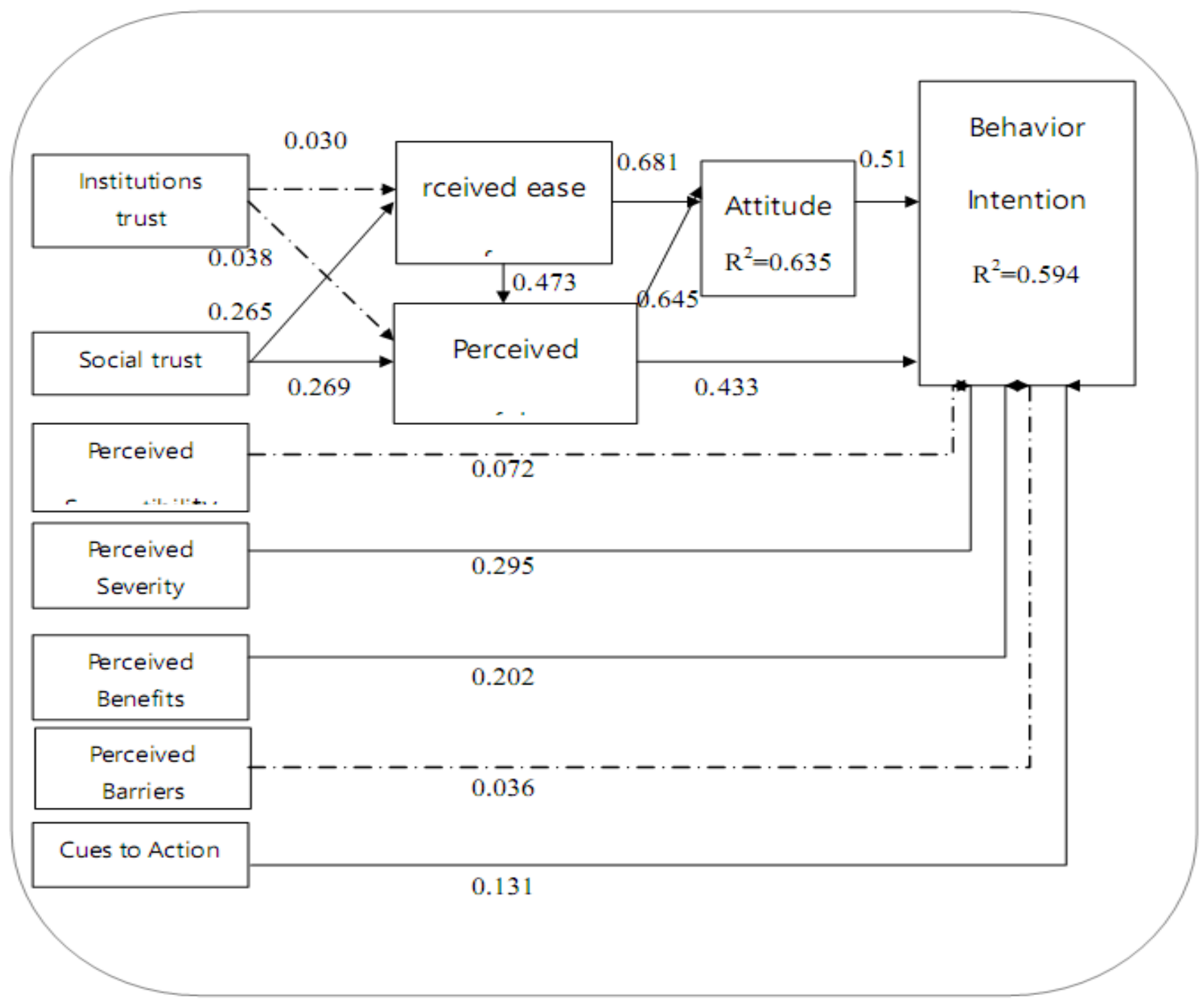

Figure 3: Path Analysis 


\section{viii. Hypothesis Testing Results}

Statistical analysis of the data via $t$ value, $p$ value and other structural equation modeling in Table 8 show that based on the results of this study, hypothesis
1 , hypothesis 2 , hypothesis hypothesis test 13 of 10 do not hold. The other hypotheses are all set up test results. The results are described below in detail.

\section{Table 8: Hypothesis Testing Results}

\begin{tabular}{|c|l|c|}
\hline Number & \multicolumn{1}{|c|}{ Hypothesis } & Result \\
\hline H1 & $\begin{array}{l}\text { Telehealthcare system users' institutional trust has a positive effect on perceived ease } \\
\text { of use }\end{array}$ & Not valid \\
\hline H2 & $\begin{array}{l}\text { Telehealthcare system users' institutional trust has a positive impact on perceived } \\
\text { usefulness }\end{array}$ & Not valid \\
\hline H3 & $\begin{array}{l}\text { Telehealthcare system users' social trust has a positive effect on perceived ease of } \\
\text { use }\end{array}$ & Valid \\
\hline H4 & Telehealthcare system users' social trust has a positive effect on perceived usefulness & Valid \\
\hline H5 & $\begin{array}{l}\text { For telehealth users, perceived ease of use has a positive effect on perceived } \\
\text { usefulness }\end{array}$ & Valid \\
\hline H6 & $\begin{array}{l}\text { Telehealth users' perceived usefulness has a positive impact on their attitude and } \\
\text { behavior }\end{array}$ & Valid \\
\hline H7 & $\begin{array}{l}\text { Telehealth users' perceived ease of use of the healthcare system has a positive impact } \\
\text { on their attitude and behavior }\end{array}$ & Valid \\
\hline H8 & $\begin{array}{l}\text { Telehealth users' perceived usefulness of the telehealthcare service system has a } \\
\text { positive effect on behavioral intentions }\end{array}$ & Valid \\
\hline H9 & $\begin{array}{l}\text { Telehealthcare users' attitude and behavior has a positive impact on their intention of } \\
\text { use of a long-distance healthcare service system }\end{array}$ & Valid \\
\hline H10 & $\begin{array}{l}\text { Telehealth users' conscious suffering will positively affect their behavioral intentions in } \\
\text { their use of a telehealthcare system }\end{array}$ & Not valid \\
\hline H11 & $\begin{array}{l}\text { Telehealth users' conscious seriousness of the care system users positively affect their } \\
\text { behavioral intentions and use of the telehealthcare system }\end{array}$ & Valid \\
\hline H12 & $\begin{array}{l}\text { Conscious interest action in a telehealthcare system will positively affect behavioral } \\
\text { intentions and use of the system }\end{array}$ & Valid \\
\hline H13 & $\begin{array}{l}\text { The conscious mobility impairments of a telehealthcare system will negatively affect } \\
\text { the behvioral intentions and use of the system }\end{array}$ & Not valid \\
\hline H14 & $\begin{array}{l}\text { Users' action cues have a positive impact on the behavioral intentions and use of a } \\
\text { telehealthcare system }\end{array}$ & Valid \\
\hline
\end{tabular}

\section{Conclusions and Recommendations}

Findings and recommendations based on the results of this study are divided into four parts.

a) Social, Institutional Trust and Perceived Usefulness, Perceived Ease of use

Mohseni and Lindstrom's (2007) research on the relationship between trust and confidence for the sub-institution of social trust, known as institutional trust, suggests that patients do not need to have any medical expertise at the clinical or technical level. Healthcare providers give medical care, and social trust is gained by listening, respect, care, and assistance with the disease.

\section{b) Institutional Trust, Perceived Usefulness, and Ease of use}

This study hypothesized that institutional trust will positively affect the perceived usefulness and ease of use. When user trust in a telehealth system increases, this will improve the system's perceived usefulness and ease of use. The results of this study are not the same as those in Su, Tsai, and Hsu (2013). The following provides a closer discussion on this result. Su, Tsai and Hsu (2013) examine respondents from a single medical institution using the same telehealthcare system. So, in that study a long-term trust pipeline with the medical institution had already been established. However, the present study found that up to 2 percent of users of a telehealthcare system engaged with it for less than a month, and more than $50 \%$ of users for less than a year. In such a short time, telehealth users cannot adequately understand the healthcare system. This therefore may not produce a link of trust, resulting in no significant institutional situation of Telehealthcare system trust perceived usefulness and perceived ease of presentation.

In this study, telehealthcare system users who use the system for more than one year experience. The results show that for respondents using a system for 1-2 years and users of more than two years, institutional trust and perceived ease of usefulness are significant. Thus, long-term use of a telehealthcare system, is an important factor for institutional trust.

c) Social Trust and Perceived Usefulness and Ease of use

The study hypothesizes that that social trust will positively affect perceived usefulness and ease of use. Social trust in a telehealthcare system should increase if 
relative usefulness will be to raise awareness and ease of use. This result is the same. Su, Tsai and Hsu (2013) studied institutional trust and social trust in the technology acceptance model. The current results show these to be important factors.

\section{d) Perceived Ease of use and Perceived Usefulness}

The hypothesis is that perceived ease of use will positively affect the perceived usefulness. If the user's perceived ease of use increases, perceived usefulness will also increase. The results of this study are the same as those in Davis (1993), Igbaria et al. (1997) and Sørebø and Eikebrokk (2008). This means id users do not need to spend a lot of time to learn how to operate a telehealthcare service system, they will feel that the system is useful.

\section{e) Attitude and Behavior, Perceived Usefulness}

The hypothesis is that perceived usefulness will positively affect behavior and attitude. When the user's knowledge and usefulness improves, behavior and attitude will also improve. The results of this study are the same as those in Davis (1993), Igbaria et al. (1997), and Mathieson et al. (2001). This means that if people believe the telehealthcare system can enhance their health, they will have a higher willingness to use the system.

f) Perceived Usefulness, Perceived Ease of use, and Behavior and Attitude

The hypothesis is that perceived ease of use will positively affect behavior and attitude. When user ease if cognitive improvement relative behavior and attitude will improve. The results of this study are the same as those in Davis (1993), Igbaria et al. (1997), and Mathieson et al. (2001). Information technology that can effectively improve work efficiency and does not take much effort to learn will result in a more positive experience. If we can effectively improve the care system for personal health to reduce pain without too much effort, users of the telehealthcare system will have more positive attitudes.

\section{g) Perceived Susceptibility and Behavioral Intention}

The hypothesis is that consciously suffering from sex will positively affect the behavioral intentions. If the user's conscious suffering of the increase, will increase relative behavioral intentions. The results of this study and those of Rosenstock et al. (1988) are not the same. The following provides further discussion of this result.

The health belief model of conscious suffering description of the individual to perform an action or the possibility of taking an act, by the possibility of a disease in itself for the possibility of suffering from cognitive could directly lead to individual actions, but through this study descriptive statistics Information found most of the user frequency of once a week to account for up to $48.9 \%$, showing the majority of users themselves may chronic diseases, not because of fear of their own because of the potential danger of suffering from a particular disease and the use of habit Telehealthcare system.

\section{h) Perceived Severity and Behavioral Intention}

The hypothesis is that perceived severity will positively affect behavioral intentions. If the user's conscious seriousness improves, behavioral intentions will increase. The results of this study are the same as those in Becker (1974) and Anderson (1968). This means when one feels there are some underlying risk factors, one will tend to seek a physical exam or other healthy behaviors.

\section{i) Perceived Benefits and Behavioral Intention}

The study hypothesis is that conscious action will positively affect the interests of behavioral intentions. Conscious action represents the interests of a longdistance healthcare system if the user increased relative will improve behavioral intentions. The results of this study and other academic and Bandura (1997a). Faith will be affected by norms and pressure on individuals, and different social groups act differently. In the health belief model, the stronger one's conscious interest in an action, the easier it is to perform the action. So, benefits of a telehealthcare system are brought people's attention, for example its use in mitigating a disease or its symptoms or increased quality of life, then users will be more likely to continue to engage with the system.

\section{j) Perceived Barriers and Behavioral Intention}

The hypothesis is that conscious intent will negatively affect behavior. This represents a conscious action of the barriers to a telehealth user if the increase will be reduced relative to their behavioral intentions. Results of this study and Rosenstock (1966) are not the same. The following provides a closer discussion of this result.

Obstacles conscious action means hinder the implementation of health and costs arising out of acts required to spend will reduce personal health-seeking behavior change intentions. So Telehealthcare service in promoting, there may be to make use of this system to produce spending behavior, and thus reduce their willingness to use this system of. A comparison of the results of this study with those of previous scholars are summarized as follows:

Most respondents to the questionnaire who will use the computer network, and therefore presumably lower disturb system operations.

Most medical institutions send a medical car into the community to provide services for residents so people do not incur a high cost.

Most of the home-based healthcare services involved in long-distance service have a lower initial 
cost, but in this study more than half of the users are in their first year of experiencing telehealthcare systems and services.

\section{k) Cues to Action and Behavioral Intention}

The hypothesis is that action cues will positively affect behavioral intentions. If cues to action are improved, behavioral intention will increase. The results of this study are the same as those in Rosenstock (1966) and Falomir (1999). This means personal effects, such as physical discomfort, symptoms, and the outer clue refers to the social impact, including physician recommendations, relatives or encouragement from the media or education. Action cues can effectively help change health behaviors.

\section{I) The Summary of the Overall Structure of the Model}

First, perceived usefulness, perceived ease of use, and the high ratio of social trust and institutional trust all influence perceived usefulness. Trust has relatively no influence on behavior and attitude. The influence of perceived ease of use on perceived usefulness is high. With respect to behavioral intentions, behavior and attitude than perceived usefulness, perceived severity, perceived benefits of action and action cues influence to high.

Overall, current long-distance healthcare is promoted fro mainly those "aging in place", so that the elderly or chronically ill can get the best medical care at home or in their community. Meanwhile, with the progress of Information Section Infotek, the Internet or smart phone APP product innovation, but also to traditional telemedicine towards personal health management autonomy. Governmental agencies and system vendors should strengthen future relationships of trust between each user and the system's interface to ensure it is easy to operate as part of its main design. In the future, we believe that telehealthcare system users will increasingly be able to manage their own health. How to advocate and allow users to accept these systems as the future of healthcare is an important issue faced by today's medical institutions.

The age of respondents in this study falls mostly between 41 to 64 years, $56.3 \%$ of the sample, followed by those 21 to 40 years, $26.8 \%$ of the sample. Questionnaire respondents were therefore mainly young and middle aged, but with an increasingly aging population, medical groups will probably be 65 years old or older. Further research may be directed to explore the experiences of more elderly users.

In addition, different users may have different concerns including high blood pressure, diabetes, heart disease. This will result in different behavioral intentions for the use of telehealthcare system and can be a research direction for subsequent studies.

The study variables included 11 factors and questionnaires were collected. In order to ensure quality and taking into account the survey respondents as older users, the questionnaire was designed with only 39 questions making it more difficult to understand the influencing factors. It is recommended that future studies increase the number of items in order to truly understand and analyze the responses. In addition, qualitative interviews can be used to understand system users.

\section{References Références Referencias}

1. Ajzen, I. (1985). From Intention to Actions: A Theory of Planned Behavior. In J. Kuhl and J. Bechmann (Eds.), Action-Control: From Cognition to Behavior, 11-39. Springer, Heidelberg.

2. Ajzen, I., \& Fishbein, M. (1980). Understanding Attitudes and Predicting Social Behavior. PrenticeHall, Englewood Cliffs, NJ.

3. Bandura, A. (1977). Self-Efficacy: Toward a Unifying theory of Behavioral Change. Psychological Review, 84(2), 191-215.

4. Becker, M. H. (1974). The Health Belief Model and Sick Role Behavior. Health Education Quarterly, 2, 409-419.

5. Boon, S.D., \& Holmes, J.G. (1985). The Dynamics of Interpersonal Trust: Resolving Uncertainty in the Face of Risk. in Robert A. Hinde \& Jo Groebel (eds.), Cooperation and Personal Behavior, New York: Cambridge University.

6. Burtt, K. (1997). Nurses Use Telehealth to Address Rural Healthcare Needs, Prevent Hospitalizations. American Nurse, 29(6), 21.

7. Cavallo, F., Aquilano, M., \& Arvati, M. (2015). An ambient assisted living approach in designing domiciliary services combined with innovative technologies for patients with alzheimer's disease: A case study. American Journal of Alzheimer's Disease and Other Dementias, 30(1), 69-77.

8. Chau, P.Y.K., \& Hu, P.J.H. (2002). Investigating Healthcare Professionals' Decisions to Accept Telemedicine Technology: an Empirical Test of Competing Theories. Information \& Management, 39(4), 297-311.

9. Champney, L. (1995). Introduction to Quantitative Political Science. New York: Harper Collins College.

10. Chakraborty, I., Hu, P. J.-H., \& Cui, D. (2008). Examining the effects of cognitive style in individuals' technology use decision making. Journal of Decision Support Systems, 45(2), 228-241.

11. Curtin, M., \& Lubkin, I.(1995). What is chronicity? In I. M. Lubkin (Ed.).

12. Dang, S., Gomez-Orozco, C. A., Van Zuilen, M. H., \& Levis, S. (2018). Providing dementia consultations to veterans using clinical video telehealth: Results from a clinical demonstration project. Telemedicine and e-Health, 24(3), 203-209.

13. Davis, F.D. (1989). Perceived Usefulness, Perceived Ease of Use, and User Acceptance of Information Technology. MIS Quarterly, 13(3), 319-339. 
14. Davis, F.D., Bagozzi, R.P., \& Warshaw, P.R. (1989). User Acceptance of Computer Technology: A Comparison of Two Theoretical Models. Management Science, 35(8), 982-1003.

15. Dirks, K.T. (1999). The Effects of Interpersonal Trust on Work Group Performance. Journal of Applied Psychology, 84(3), 445-455.

16. Falomir, J. M., \& Invernizzi, F. (1999). The role of social influence and smoker identity in resistance to smoking cessation. Swiss Journal of Psychology, 58(2), 73-84.

17. Farina, N., Sherlock, G., Thomas, S., Lowry, R. G., \& Banerjee, S. (2019). Acceptability and feasibility of wearing activity monitors in community-dwelling older adults with dementia. International Journal of Geriatric Psychiatry, 34(4), 617-624

18. Fishbein, M., \& Ajzen, I. (1975). Belief, attitude, intention and behavior: An introduction to theory and research, Reading, Ma: Addison-Wesley.

19. Friedman, L. C., Neff, N. E., Webb, J. A., Latham, C. K. (1998) "Age-related differences in mammography use and in breast cancer knowledge, attitudes, and behaviors," Patient Education and counseling, 33, 26-30.

20. Fung, S.Y. (1998). "Factors associated with breast self-examination behaviour among Chinese women in Hong Kong," Patient Education and Counseling, 33(3), 233-243.

21. Gately, M. E., Trudeau, S. A., \& Moo, L. R. (2020). Feasibility of Telehealth-delivered home safety evaluations for caregivers of clients with dementia. OTJR: Occupation, Participation and Health, 40(1), 42-49.

22. Hair, J. F., Black, W. C., Babin, B. J., \& Tatbam, R. L. (2006). Multivariate Date Analysis. New Jersey: Person Education.

23. Holthe, T., Halvorsrud, L., Karterud, D., Hoel, K. A., \& Lund, A. (2018). Usability and acceptability of technology for community-dwelling older adults with mild cognitive impairment and dementia: A systematic literature review. Clinical Interventions in Aging 13, 863-886.

24. Igbaria, M., Zinatelli, N., Cragg. P., Cavaye, A. (1997). Personal computing acceptance factors in small firms: a structural equation model. MIS Quarterly, 21(3), 279-302.

25. Janz, N.K., Champion, V.L., \& Strecher, V.J. (2002). The Health Belief Model, In: Glanz, K., Rimer, B.K. and Lewis, F.M. (eds), Health Behavior and Health Education: Theory, Research, and Practice, San Francisco, CA: Jossey-Bass Publishers.

26. Kikhia, B., Stavropoulos, T. G., Meditskos, G., Kompatsiaris, I., Hallberg, J., Savenstedt, S., \& Melander, C. (2018). Utilizing ambient and wearable sensors to monitor sleep and stress for people with BPSD in nursing homes. Journal of Ambient Intelligence and Humanized Computing, 9, 261-273.
27. Kovner, R., Hardy Havens, D. M. (1996). Telemedicine potential applications and barriers to continued expansion. Journal of Pdiatric Healthcare, 10(4), 184-187.

28. Kowitlawakul, Y. (2011). The Technology Acceptance Model Predicting Nurses' Intention to Use Telemedicine Technology (elCU)). CIN: Computers, Informatics, Nursing, 29 (7), 411-418.

29. Kuo, R.L., Delvecchio, F.C., Babayan, R.K., \& Preminger, G.M. (2001). Telemedicine: Recent developments and future applications. Journal of Endourology, 15(1), 63-66.

30. Legris, P., Ingham, J., \& Collerette, P. (2003). Why do People Use Information Technology? A Critical Review of the Technology Acceptance Model. Information \& Management, 40(3), 191-204.

31. Lu, Ju-Fen, Chen, Ching-Min and Hsu, Chien-Yeh, Effect of home telehealth care on blood pressure control: A public healthcare centre model, Journal of Telemedicine and Telecare, 2019, Vol. 25(1) 35-45.

32. Mathieson, K., Peacock, E., Chin, W.W. (2001) Extending the technology acceptance model: the influence of perceived user resources. The DATA BASE for Advances in Information Systems, 32(3), 86-112.

33. Mohseni, M. \& Lindstrom M. (2007), "Social capital, trust in the health-care system and self-rated health: the role of access to healthcare in a populationbase study, "Social Science \& Medicine, 64, 1373-1383.

34. Pai, F.Y., \& Huang K.I. (2011). Applying the Technology Acceptance Model to the Introduction of Healthcare Information Systems. Technology Forecasting and Social Change, 78(4), 650-660.

35. Rosenstock, I. M. (1974). Historical origins of the health belief model. Health Education Monographs, 2(4), 328-335.

36. Rosenstock, I. M., Strecher, V. J., \& Becker, M. H. (1988). Social learning theory and the health belief model. Health Education Quarterly, 15(2), 175-183.

37. Sørebø,O., \& Eikebrokk, T. R. (2008) Explaining IS continuance in environments where usage is mandatory. Computers in Human Behavior. 24(5), 2357-2371.

38. Su, Tsai, \& Hsu. (2013). Extending the TAM Model to explore the Factors Affecting Intention to Use Telecare System. Journal of Computers, 8(2), 525-532.

39. Teo, T.S.H., Srivastava, S.C., \& Jiang, I. (2008). Trust and Electronic Government Success: An Empirical Study. Journal of Management Information Systems, 25(3), 99-131.

40. Thorne, S.E., \& Robinson, C.A. (1988). Reciprocal Trust in Healthcare Relationships. Journal of Advanced Nursing, 13(6), 782-789.

41. Vijayasarathy, L.R. (2004). Predicting consumer intentions to use online shopping: the case for an 
augmented technology acceptance model. Information and Management, 41(6), 747-762.

42. Vito, Alyssa N. De, Sawyer II, R. John, La Roche, Ashley, Arredondo, Beth, Mizuki, Brian and Knoop, Colleen, Acceptability and Feasibility of a Multicomponent Telehealth Care Management Program in Older Adults With Advanced Dementia in a Residential Memory Care Unit, Gerontology and Geriatric Medicine, Volume 6: 1-8, June 10, 2020.

43. Wixom, B.H., \& Todd, P.A. (2005). A Theoretical Integration of User Satisfaction \& Technology Acceptance. Information Systems Research, 16(1), 85-102.

44. Yousafzai, S.Y., Foxall, G.R., \& Pallister, John, G. (2010). Explaining Internet Banking Behavior: Theory of Reasoned Action, Theory of Planned Behavior, or Technology Acceptance Model?. Journal of Applied Social Psychology, 40(5), 1172-1202. 